\title{
Usability and Learning Environment of a Virtual Reality Simulator for Laparoscopic Surgery Training
}

\author{
Karina Rosas-Paredes ${ }^{1}$, José Esquicha-Tejada ${ }^{2}$, Héctor Manrique Morante ${ }^{3}$, Agueda Muñoz del Carpio Toia ${ }^{4}$ \\ Systems Engineering Program, Universidad Católica de Santa María, Arequipa, Perú1, 2, 3 \\ Medicine, Universidad Católica de Santa María, Arequipa, Perú ${ }^{4}$
}

\begin{abstract}
One of the critical aspects of laparoscopic surgeries is the training and learning of medical students to acquire the experience and the correct use of the equipment, which is usually difficult due to different circumstances. One of the ways to improve these activities is by using Virtual Reality technology that allows immersion in scenarios that simulate reality, but to achieve its correct use, it is necessary to consider usability and its learning environment. This work aims to develop a simulator software in Virtual Reality that allows the training and learning of students in laparoscopic surgery, evaluating its usability and learning environment. The proposal was developed in five levels so that the student can have a greater concentration on each task; The levels developed are: clamps, clamps for the camera, cut, cut camera and cut with clamps; Each level has different tasks to perform with which the student will be able to interact in a more orderly way. The evaluation of usability and learning environment was carried out through the survey technique using the questionnaire instrument. The reliability analysis of the instrument was carried out using Cronbach's alpha test and using the correlation coefficient of its items by Spearman. The results showed that $85.85 \%$ of the surveys carried out were positive for the learning environment area and $81.18 \%$ of the positive surveys for the Usability area, so it is concluded that the proposal developed can help in the training of medical students procedurally and practically for the development of skills in laparoscopic surgery.
\end{abstract}

Keywords-Usability; learning environment; virtual reality; training; simulator; medical; laparoscopic surgery

\section{INTRODUCTION}

Laparoscopic or minimally invasive surgery is a surgical technique widely used today, either because it has few postoperative complications or because of the postoperative hospital stay [1]. However, for the mastery of this technique, it is necessary to adapt to the management of various instruments, techniques, and acquisition of skills, which can only be obtained through practice; this requires additional training in surgical skills to face advanced technological challenges [2]; currently, an alternative to this problem is acquired by the use of inanimate simulators, virtual simulators of high cost and direct management of patients in the operating room, which makes it difficult for doctors and students in general [3].

Virtual Reality (VR) simulations is a technology that has expanded in recent years with many advantages in different fields, such as medical education, by allowing virtual immersion in a given environment [4].
Besides, the interruption in the education of medical students during COVID-19 has been inevitable worldwide; for this reason, educational strategies must be developed to retain clinical skills, abilities, and knowledge [5], and that covers the limitations of the methods more traditional, especially in surgical procedures such as laparoscopic.

For this reason, the objective of this work is to develop a simulation software in Virtual Reality that allows the training and learning of students in laparoscopic surgery that allows them to practice challenging and significant procedures repeatedly and save the cost of training, evaluating its usability and learning environment; We will use tools such as Unity together with a helmet or glasses to generate three-dimensional images of simulated reality to allow immersion in a virtual medical environment. The usability and learning environment will be carried out through the survey technique using the questionnaire instrument. The reliability analysis of the instrument will be carried out using Cronbach's alpha test and using the correlation coefficient of its items by Spearman.

The rest of this paper is organized as follows: The second part is the background and related work. The third part describes the research material and method. The fourth part presents the results of this research. Finally, the conclusions and future work that has been reached with the study.

\section{RELATED WORK}

Different works on virtual reality were reviewed, its factors, oriented to the field of health, we highlight the most relevant.

The work of Pfandler et al. [6] carried out a systematic review of the current scientific literature regarding VR-based simulation in spinal surgery, where the quality of current studies and existing research is evaluated. In addition, to guide future studies evaluating virtual reality-based simulators in this field.

In the studies reviewed about student-oriented virtual reality simulation, Rizzo et al. [6] consider that this technology offers many advantages in the clinical area. Virtual environment technology provides a controlled stimulus where cognitive challenges can occur and the precise delivery and control of auditory and visual stimuli that simulate reality. Liou and Chang [7] developed a virtual reality classroom to improve student performance and learning outcomes. A virtual reality learning environment was developed, which integrates virtual reality technology, virtual reality devices, and 3D interactive virtual reality digital information content. To evaluate the 
effectiveness of the proposed design, students' performance in terms of learning achievement and learning motivation was examined. The results of this virtual reality classroom showed significantly better learning motivation.

Regarding the use of VR in the medical field, in the work of Izard, Juanes, and Penalvo [4] they point out that Virtual Reality is being integrated into many different areas of our lives, from video games to different cases of industrial use and, of course, it is beginning to be used in medicine; they analyzed how these systems can improve current methodologies used for medical training. VR has seen steady growth in medicine in recent years [8]. According to Chheang et al. [9], VR has been used in many medical training systems for surgical procedures. However, current systems are limited due to inappropriate interactions, restricted patient data visualization capabilities, and collaboration. So a collaborative virtual reality system can aid laparoscopic liver surgical planning and simulation.

For the virtual reality factors used in the simulations, the work of Servotte et al. [10] points out the factors that affect immersion and the feeling of presence in virtual reality. This study aimed to understand the elements that influence the sense of presence among undergraduate and graduate health students. The students were immersed in a simulated immersion in a mass casualty incident. Participants completed questionnaires before (propensity for immersion, stress) and after immersion (sense of presence, stress, cyberspace, and satisfaction). The results were that the sensation of presence was high among the evaluated groups and was positively correlated with the propensity to immerse.

A proof of the advantages of surgery training in virtual reality is the study by Vazquez-Minero et al. [11] performed on residents of cardiothoracic surgery, where a virtual reality simulator was used once a week for a total of 30 weeks where surveys were applied to measure the results, this study showed that the use of simulation as part of teaching is useful in the transmission and assimilation of knowledge, skills, and attitudes, however, in many specialties its use is just beginning, this is the case of chest surgery. A virtual reality simulator has also been created focused on bronchoscopy for residents of the independent specialty of the training year, achieving an improvement in their practices and safety after using the simulator. In conclusion, the use of simulation is an invaluable tool in the teaching process.

The paper of Jin, Dai, and Wang [12] indicates that virtual reality becomes popular in laparoscopic surgery, especially in the training process. The reviewed studies recommended applying virtual reality to inexperienced medical students or novice surgeons in laparoscopic training, where there was a steeper learning curve than traditional and untrained training.

For usability in VR environments, studies such as the one by Pierce et al. [13] determine the efficiency and satisfaction components of usability. Previously, it was found that firstyear medical students who used a virtual reality simulation for medical education demonstrated effectiveness in learning. Training within the virtual simulation environment can be qualified as a practical educational approach [14].
Immersive VR laparoscopy simulation is emerging to enhance the attractiveness and realism of surgical procedure training. In the paper of Ganni et al. [15], the usability and presence of a virtual operating room were reviewed through user evaluation, and the critical elements for immersive environments were established during laparoscopic procedure training. Thirty-seven surgeons and surgical trainees performed the entire cholecystectomy task on the application. Questionnaires followed by a semi-structured interview were used to collect the data. The participants were able to adapt to the application intuitively and were satisfied with their tasks; the participants, particularly the surgical trainees, were very committed to performing the task. Despite the higher mental workload in four subscales ( $\mathrm{p}<$; 0.05), the surgical trainees had a lower learning effort ( 4 vs. 3.33, p <; 0.05) compared to the surgeons. The participants experienced very mild discomfort in seven body segments (0.59-1.16). Additionally, they expected improvements for team interaction and personalized experience within settings. The system showed potential to become a useful tool to provide immersive training during simulation of the laparoscopy procedure based on usability and presence observed in the study.

According to Taba et al. [16], VRS-based teaching is expanding in medicine due to the limitations of more traditional methods, especially for surgical procedures. There are already several areas, such as neurosurgery, ophthalmic surgery, and digestive endoscopy, considering implementing this technology in their training plans. The field of laparoscopic surgery also follows this trend, with conclusions that vary from study to study. Overall, the reviews conclude that RSV is a method with the potential to develop various surgical skills.

As described, most jobs vary according to the Virtual Reality approach to teaching college students. Of the reviewed studies, we saw that some are oriented to the medical field. Given the importance of adequately training and educating medical students, it is for this reason that the intention is to build an interactive virtual reality environment for simulated training in laparoscopic surgery.

\section{MATERIAL AND METHOD}

For the construction of the medical VR simulator software, the agile Scrum methodology [17] will be used, which allows complying with the development of the application step by step of the proposed system, which was adapted according to the changing characteristics of the project. Fig. 1 shows a typical Scrum Project.

\section{A. Proposed Software Architecture}

Fig. 2. shows the software architecture that will be used to develop the VR simulator and how it provides support for the development of virtual reality applications and other Apps using the Unity multiplatform video game engine [19].

The proposal is focused on university-level students who can use virtual reality to learn the process of laparoscopic surgery. Two types of users have been identified: the student and the administrator. 


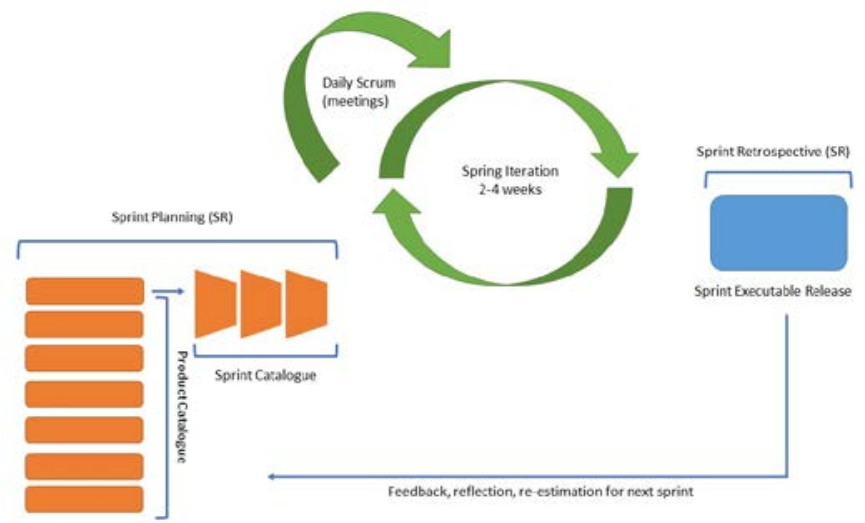

Fig. 1. Typical Scrum Project [18].

\section{Unity XR Tech Stack}

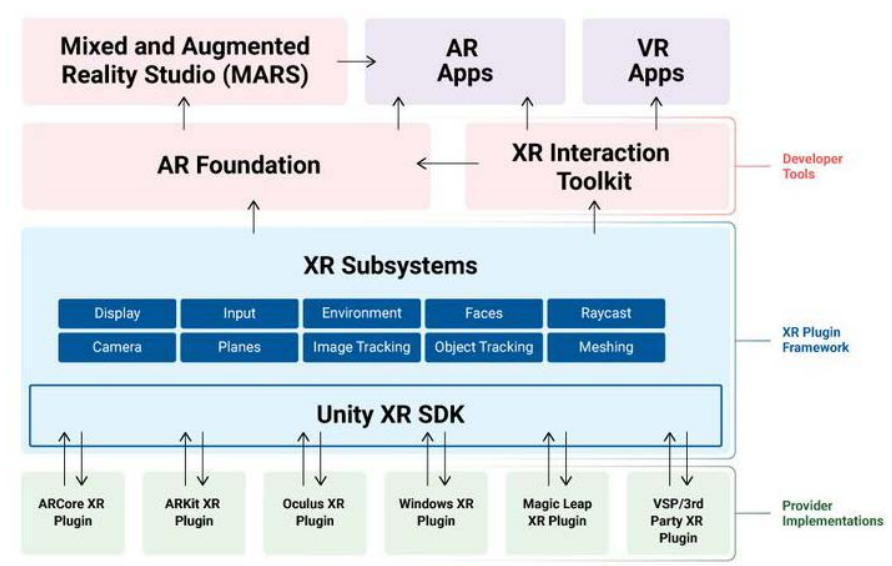

Fig. 2. Unity VR Application Software Architecture [20].

In terms of competencies and abilities, students must achieve learning progress defined by educational objectives focused on acquiring different competencies. The proposal consists of two sites, the virtual laparoscopic surgery environment, and the central system.

The student accesses different scenarios through the virtual reality glasses to carry out the training remotely, and an administrator will be able to access the information generated by the student with which they will evaluate their academic performance. This information is composed of the student's interactions in the virtual environment, the time it takes to perform the exercises, and feedback on her performance.

The interactions with the virtual environment are obtained based on the objects with which it interacts through the controls, the time is calculated from when the student begins the activity until it ends, and the performance feedback is measured based on the errors made. The student will send the information after finishing an activity; the information will be saved through a web database in which the information will be stored which can then be accessed through reports.

\section{B. Components of the Proposed System}

This section presents the details of the development of the proposed system and of each of its components. The connection of these components is seen in Fig. 3.

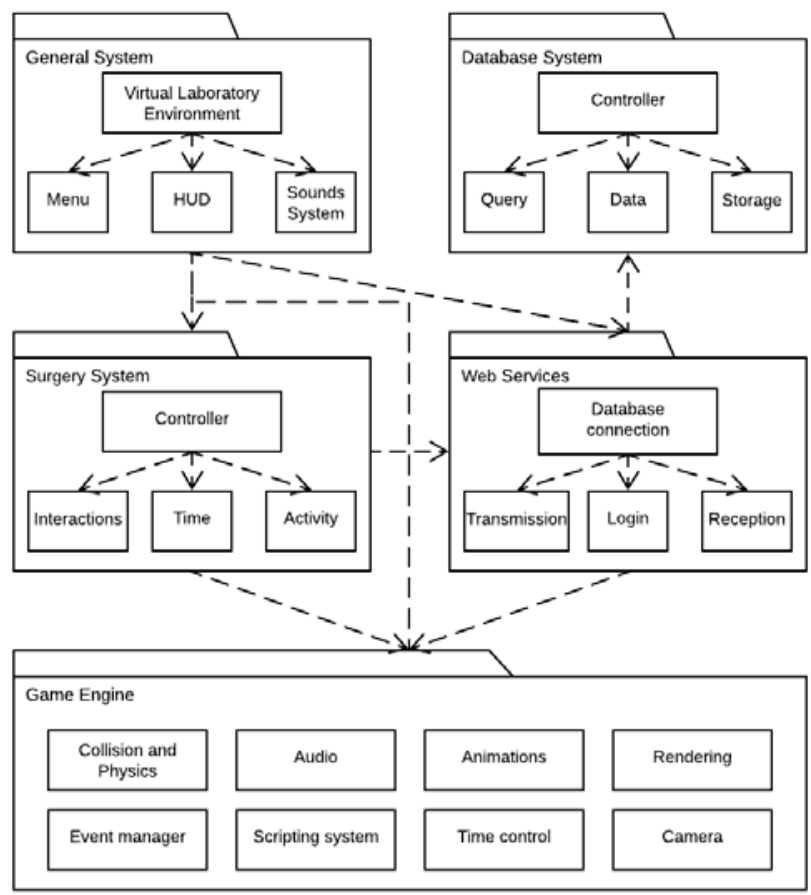

Fig. 3. Components of the Proposed System.

- General System: This is the essential component of the proposed system. Since it encapsulates all the necessary elements for the use of the application, such as the menus where you can standardize the pop-up windows and messages shown in the application, HUD which allows adapting the icons and buttons to the size of the screen, the sound system that allows the reproduction of background music and the reproduction of sound effects such as clicking buttons and, in the event that an activity is solved, a sound of success or error and the virtual environment where the operating room of a hospital is simulated, Different 3d models have been used to represent medical personnel, medical instruments and an operating room setting.

- Surgery System: This module contains a control that allows access to the different elements of each activity, allows assigning different actions to the controls, collecting the information from the controls, and generating different actions according to the type of tool selected; it also controls the time to complete each activity, how the elements of the environment react before user interactions and if the activity has been completed.

- Web service: This module is responsible for the reception and transmission of data between the application and the web database, analyzes the user's interactions to the system, and is stored in a predefined database table on the server, the benefit of using a database. Web data it is possible to share the information of different clients. 
- Database server: A web database server that stores information in predefined tables and responds to queries when necessary. To access the server, access is given.

- Game Engine: This module contains all the functions that are carried out in the development software such as collision and physics system, audio control, image rendering system, an event handling system, a scripting system for code handling, a controller of time that allows controlling the time that has elapsed and a canvas system with which the menus are controlled.

\section{Implementation of the Proposed System}

The proposed system has been implemented as a prototype of which the software used for development will be explained, the requirements to be used, and a scene where laparoscopic surgery training is carried out.

The software used for the development of the proposed system was the Unity game engine; the system was created in conjunction with professors from the medical area of the Universidad Católica de Santa María (UCSM) of ArequipaPeru; the activities of the system were based on the training carried out in the laboratory practices.

The system hardware consists of a computer that has an i5 processor or similar, an NVIDIA GTX 1060 or similar graphics card, which will be used in conjunction with an Oculus Rift that allows the use of virtual reality and interaction with the system; it was decided choose the oculus rift because wanting to simulate the interactions of medical students with surgical instruments requires greater precision and realism [21].

Before using the application, the user must calibrate the Oculus Rift, which has different sensors that must be connected to the computer and create the workspace.

\section{Virtual Laparoscopic Surgery}

The application will teach students about how to use medical instruments to perform the surgery correctly; the application will have different levels which represent the learning sessions where different tools will be used; we will describe the activity of each level below:

- Tweezers activity: It is the first level of the lessons, in which students learn to use the tweezers to pick up objects in the virtual environment; the tweezers will be represented with a realistic model which will be animated and move according to how the virtual reality control is pressed, In this activity, you will be given a series of objects that the player must place on a metal tray, the player must control the pressure that he gives to the clamp in order to avoid damaging the object or that it slips from the tweezers as seen in Fig. 4.

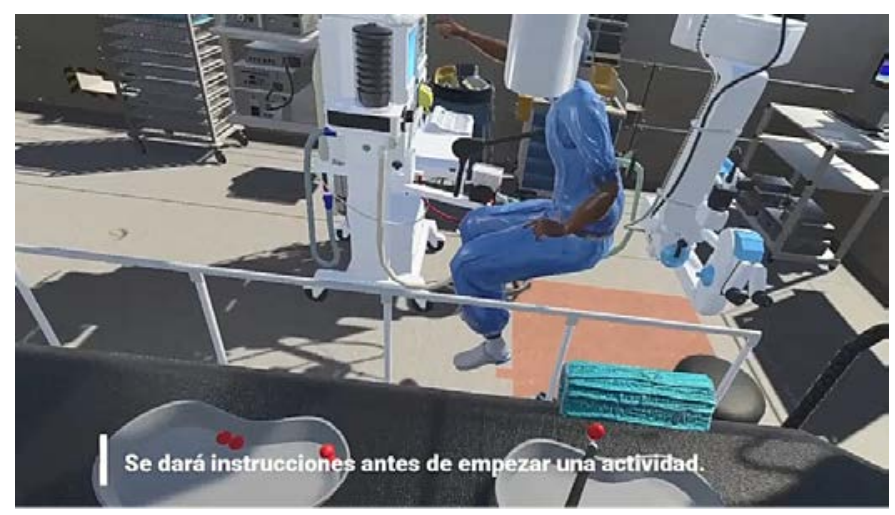

Fig. 4. Tweezers Activity Scene.

- Camera tweezers activity: In this second level, the use of tweezers will continue, but instead of working with a visible object in the scene, it will be done with an object that can only be seen through a monitor; this is done to simulate how it is done. When having a limited vision of the object in surgery, the student will have to remove the object and place it on a tray, avoiding that it falls, as seen in Fig. 5.

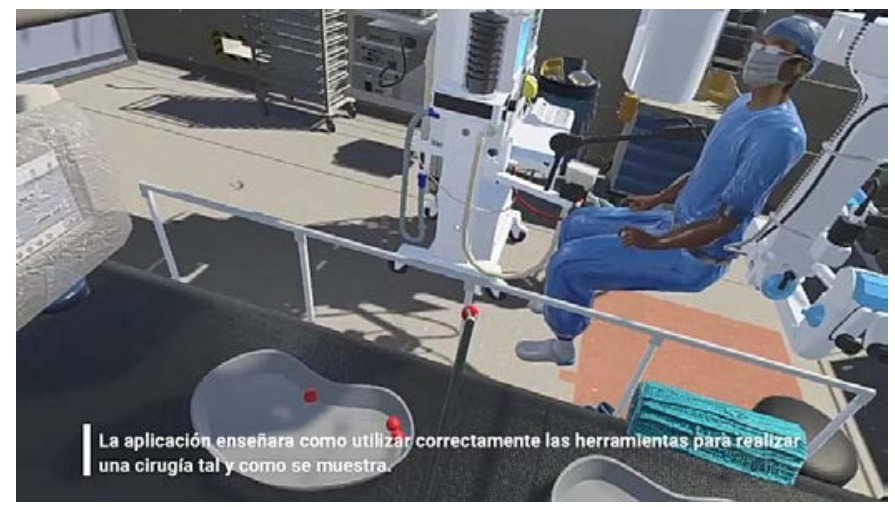

Fig. 5. Camera Tweezers Activity Scene.

- Cut activity: In this third level, the student must change the tool to be used and select a scalpel with which he must cut an object in different selected areas, as shown in Fig. 6.

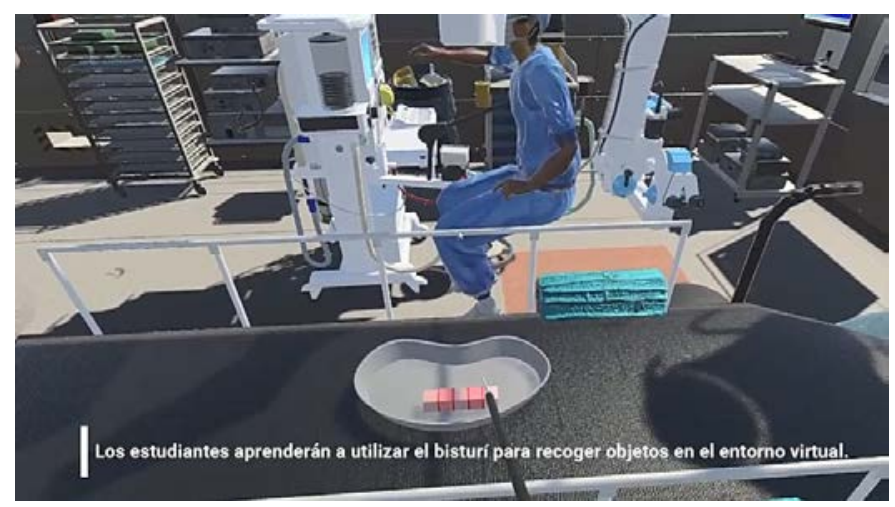

Fig. 6. Cut Activity Scene. 
- Camera cut activity: In this fourth level, the student must use the scalpel to make cuts in specific areas of an object, but to carry out this activity, the student will have limited vision since they can only see the object through a monitor, as shown in Fig. 7.

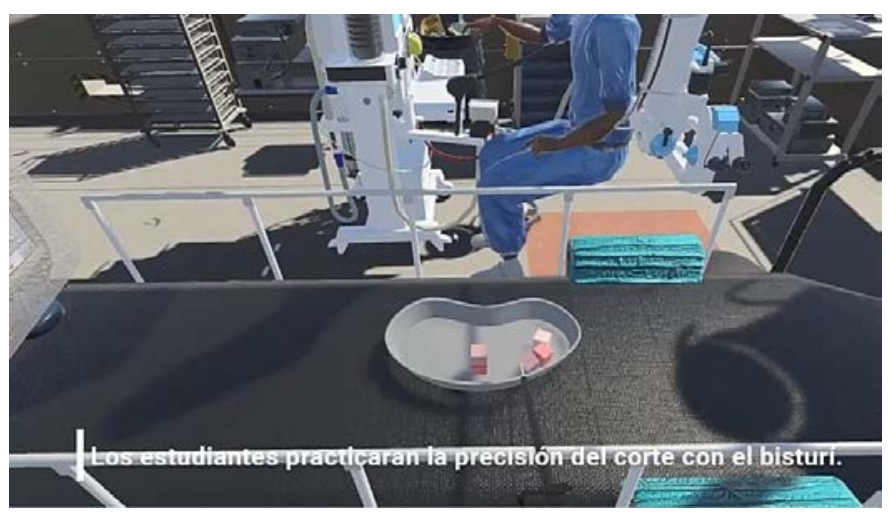

Fig. 7. Camera Cut Activity Scene.

- Tweezers and cutting activity: In this fifth level, the student must collect objects with the use of tweezers and with the other hand uses a scalpel to cut the object in order to extract it; at this level, the player will use both hands to extract an object, After having removed the object, it should be placed on a tray as shown in Fig. 8.

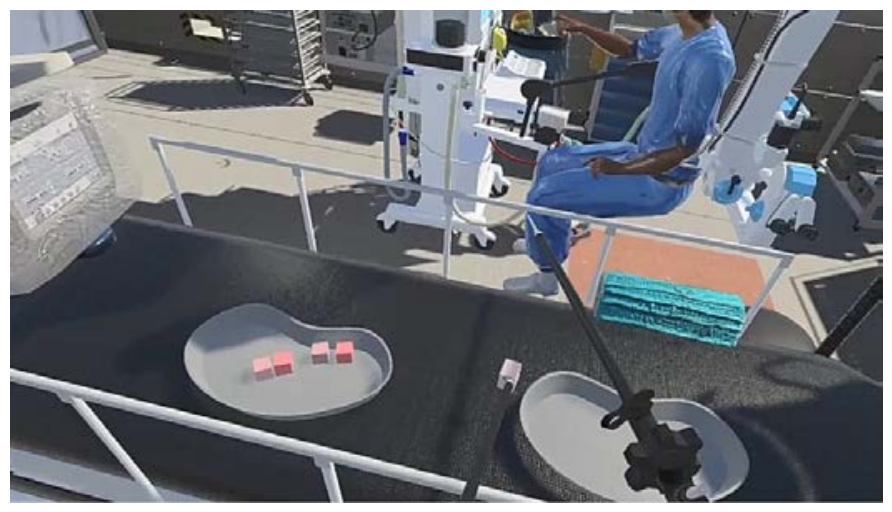

Fig. 8. Tweezer and Cut Activity Scene.

\section{RESUlts}

Participants in the experiment were surveyed to measure their learning in virtual environments and usability in virtual reality applications and the problems encountered.

The questionnaire used was to respond mainly to two research questions 1 ) to evaluate users' attitudes towards the VR application as a learning environment; and 2) to evaluate the usability of the VR application. Users are evaluated on the measurement items for each point.

\section{A. Learning Environment}

To evaluate the learning environment, eleven measurement categories are being used, which can be observed in Table I [22].
TABLE I. CRITERIA OF LEARNING ENVIRONMENT

\begin{tabular}{|l|l|}
\hline $\mathbf{N}^{\circ}$ & Measurement Items \\
\hline 1 & Immersion in the application \\
\hline 2 & Realistic learning \\
\hline 3 & Interaction with objects \\
\hline 4 & Educational Utility \\
\hline 5 & Ease of use of the application \\
\hline 6 & Feeling of being there \\
\hline 7 & Motivation in learning \\
\hline 8 & Intention to use the application \\
\hline 9 & Cognitive benefits \\
\hline 10 & Perceived Learning Effectiveness \\
\hline 11 & Satisfaction when using the application \\
\hline
\end{tabular}

\section{B. Usability of Virtual Reality Applications}

To evaluate usability, usability heuristics were analyzed, and 12 measurement categories are used, as shown in Table II [23].

Twenty-seven surveys were conducted made up of students, teachers, and graduates of the UCSM medical career. The responses were categorized within a Likert-type scale, with values from 1: Disagreement to 5: Agree. Taking the results of the surveys, we obtained that in the Learning Environment, the respondents partially agree with the application, having a percentage of $49.49 \%$, as can be seen in Fig. 9.

In the area of learning environment, it was obtained that in the question "Ease of use of the application: Was the application understandable and did you manage to understand it easily? More positive responses were obtained from our application, which 51\% are "Agree" and 44\% "Partially agree," obtaining only $5 \%$ negative responses, instead of the question Satisfaction when using the application: Are you satisfied with the learning experience that educational software provides? " is where we need to improve in our application.

TABLE II. USABILITY CRITERIA FOR VIRTUAL REALITY APPLICATIONS

\begin{tabular}{|l|l|}
\hline $\mathbf{N}^{\circ}$ & Criteria \\
\hline 1 & Level of realism in the virtual environment \\
\hline 2 & Level of realism when performing tasks \\
\hline 3 & Freedom of movement \\
\hline 4 & Response time on the screen \\
\hline 5 & Realism in physics \\
\hline 6 & Perception level \\
\hline 7 & Navigation level and orientation \\
\hline 8 & Ease of iput and output \\
\hline 9 & Understandable menu \\
\hline 10 & Ease of use \\
\hline 11 & Organized and understandable tasks \\
\hline 12 & Presence \\
\hline
\end{tabular}




\section{Learning Environment}

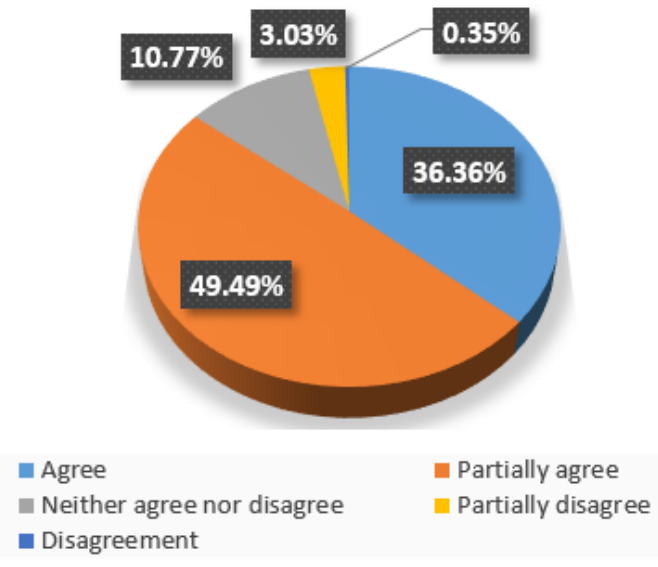

Fig. 9. Results of the Surveys on the Learning Environment.

Regarding the usability of virtual reality, we obtained that the respondents partially agree with $53.40 \%$, as can be seen in Fig. 10.

Virtual Reality Usability

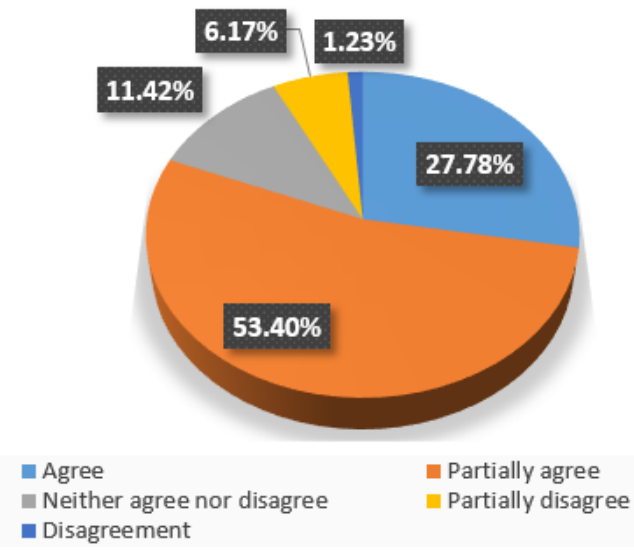

Fig. 10. Results of Surveys on the usability of Virtual Reality.

In the area of virtual reality usability, it was obtained that in the question "Tasks organized and understandable, do you consider that the tasks in the simulator are organized and understandable to complete the activity?" The most positive responses of the application were 55\% for "Agree" and $44 \%$ "Partially agree," obtaining only $1 \%$ negative responses, on the other hand, in the question "Feeling of being present in the virtual world: Do you feel that you are present in the virtual world in a natural way? " it is where it has to be improved in the proposed VR application.

The reliability of the internal consistency of the measurement elements of the questionnaire was evaluated by calculating Cronbach's alpha $(\alpha)$ test based on the variance of the instrument items [24]. Alpha reliability was considered acceptable, with values ranging between 0.832 for the Learning Environment (Table III) and 0.898 for the Usability of Virtual Reality (Table IV). In addition, the mean and standard deviation (S.D.) of the elements have been generated.
The Spearman correlation was also performed between each measurement item of the Learning Environment and Usability of Virtual Reality measurement; the results are presented in Table V and Table VI, respectively. For the analysis of the results, the SPSS 26.0 software package was used.

There was a medium to strong positive correlation $(>0.3)$ among the majority of items with the VR characteristic of Representational Fidelity regarding the learning environment. Perceived Learning Effectiveness and Satisfaction showed a small to medium correlation effect with immersion.

Regarding usability, there was also a positive medium to strong correlation between most items. The Freedom of movement showed a small to medium correlation effect with realism in the virtual environment and with the level of realism when performing tasks.

TABLE III. QUESTIONNAIRE MEASUREMENT ITEMS: LEARNING ENVIRONMENT

\begin{tabular}{|l|l|l|l|l|}
\hline $\mathbf{N}^{\circ}$ & Measurement Items & $\boldsymbol{\alpha}$ & Mean & S.D. \\
\hline 1 & Immersion in the application & .907 & 4.15 & .534 \\
\hline 2 & Realistic learning & .879 & 4.22 & .698 \\
\hline 3 & Interaction with objects & .898 & 4.07 & .730 \\
\hline 4 & Educational Utility & .882 & 4.37 & .688 \\
\hline 5 & Ease of use of the application & .886 & 4.44 & .641 \\
\hline 6 & Feeling of being there & .890 & 4.07 & .675 \\
\hline 7 & Motivation in learning & .896 & 3.96 & 1.01 \\
\hline 8 & Intention to use the application & .877 & 4.30 & .775 \\
\hline 9 & Cognitive benefits & .889 & 4.30 & .724 \\
\hline 10 & $\begin{array}{l}\text { Efficiency of the application in } \\
\text { learning }\end{array}$ & .876 & 4.19 & .962 \\
\hline 11 & $\begin{array}{l}\text { Satisfaction when using the } \\
\text { application }\end{array}$ & .893 & 3.96 & .854 \\
\hline
\end{tabular}

TABLE IV. QUESTIONNAIRE MEASUREMENT ITEMS: USABILITY

\begin{tabular}{|l|l|l|l|l|}
\hline $\mathbf{N}^{\circ}$ & Measurement Items & $\boldsymbol{\alpha}$ & Mean & S.D. \\
\hline 1 & $\begin{array}{l}\text { Level of realism in the virtual } \\
\text { environment }\end{array}$ & .815 & 3.96 & .706 \\
\hline 2 & $\begin{array}{l}\text { Level of realism when performing } \\
\text { tasks }\end{array}$ & .820 & 3.93 & .675 \\
\hline 3 & Freedom of movement & .817 & 3.81 & .962 \\
\hline 4 & Response time on the screen & .810 & 4.00 & .961 \\
\hline 5 & Realism in physics & .804 & 3.85 & 1.06 \\
\hline 6 & Perception level & .806 & 3.59 & .888 \\
\hline 7 & Navigation level and orientation & .814 & 4.04 & .759 \\
\hline 8 & Ease of input and output & .814 & 3.89 & .892 \\
\hline 9 & Understandable menu & .826 & 4.37 & .688 \\
\hline 10 & Ease of use & .829 & 4.44 & .577 \\
\hline 11 & Organized and understandable tasks & .832 & 4.52 & .580 \\
\hline 12 & Presence & .831 & 3.63 & 1.04 \\
\hline
\end{tabular}


TABLE V. SPEARMAN CORRELATION BETWEEN THE MEASUREMENT ITEMS LEARNING ENVIRONMENT

\begin{tabular}{|c|c|c|c|c|c|c|c|c|c|c|c|c|}
\hline $\mathbf{N}^{\circ}$ & Measurement Items & 1 & 2 & 3 & 4 & 5 & 6 & 7 & 8 & 9 & 10 & 11 \\
\hline 1 & Immersion & 1 & & & & & & & & & & \\
\hline 2 & Representational Fidelity & .196 & 1 & & & & & & & & & \\
\hline 3 & Immediacy of Control & .287 & .332 & 1 & & & & & & & & \\
\hline 4 & Perceived Usefulness & .140 & .705 & .414 & 1 & & & & & & & \\
\hline 5 & Perceived Ease of Use & .247 & .501 & .579 & .818 & 1 & & & & & & \\
\hline 6 & Presence & .536 & .589 & .394 & .408 & .288 & 1 & & & & & \\
\hline 7 & Motivation & .125 & .697 & .259 & .612 & .458 & .363 & 1 & & & & \\
\hline 8 & Cognitive Benefits & .146 & .641 & .489 & .761 & .762 & .570 & .657 & 1 & & & \\
\hline 9 & Intention to use system & .351 & .506 & .403 & .495 & .500 & .611 & .286 & .677 & 1 & & \\
\hline 10 & Perceived Learning Effectiveness & .087 & .849 & .353 & .771 & .637 & .477 & .574 & .721 & .579 & 1 & \\
\hline 11 & Satisfaction & .047 & .455 & .441 & .441 & .443 & .508 & .463 & .572 & .348 & .495 & 1 \\
\hline
\end{tabular}

TABLE VI. SPEARMAN CORRELATION BETWEEN THE MEASUREMENT ITEMS USABILIDAD OF VIRTUAL REALITY

\begin{tabular}{|c|c|c|c|c|c|c|c|c|c|c|c|c|c|}
\hline $\mathbf{N}^{\circ}$ & Measurement Items & 1 & 2 & 3 & 4 & 5 & 6 & 7 & 8 & 9 & 10 & 11 & 12 \\
\hline 1 & $\begin{array}{l}\text { Level of realism in the virtual } \\
\text { environment }\end{array}$ & 1 & & & & & & & & & & & \\
\hline 2 & $\begin{array}{l}\text { Level of realism when performing } \\
\text { tasks }\end{array}$ & .332 & 1 & & & & & & & & & & \\
\hline 3 & Freedom of movement & .196 & .287 & 1 & & & & & & & & & \\
\hline 4 & Response time on the screen & .705 & .414 & .140 & 1 & & & & & & & & \\
\hline 5 & Realism in physics & .501 & .579 & .247 & .818 & 1 & & & & & & & \\
\hline 6 & Perception level & .589 & .394 & .536 & .408 & .288 & 1 & & & & & & \\
\hline 7 & Navigation level and orientation & .697 & .259 & .125 & .612 & .458 & .363 & 1 & & & & & \\
\hline 8 & Ease of entry and exit & .641 & .489 & .146 & .761 & .762 & .570 & .657 & 1 & & & & \\
\hline 9 & Understandable menu & .506 & .403 & .166 & .495 & .500 & .611 & .286 & .677 & 1 & & & \\
\hline 10 & Ease of use & .849 & .353 & .064 & .771 & .637 & .477 & .574 & .721 & .579 & 1 & & \\
\hline 11 & Organized and understandable tasks & .455 & .441 & .068 & .441 & .443 & .508 & .463 & .572 & .348 & .495 & 1 & \\
\hline 12 & Presence & .433 & -.190 & .224 & .126 & -.003 & .452 & .291 & .356 & .448 & .388 & .067 & 1 \\
\hline
\end{tabular}

\section{DISCUSSION AND CONCLUSION}

Evaluating the virtual reality simulator for laparoscopic surgery, in terms of its usability and learning experience, is very important for the successful acceptance of the training in medical students. This study used usability heuristics in 12 measurement categories and 11 measurement categories for the learning environment.

In essence, the virtual reality simulator developed and proposed presented an acceptable acceptance of usability among those who agreed (27.78\%) and partially agreed (53.40\%), as well as for the learning environment among those who agreed (36.36 \%) and partially agreed (49.49\%). These results show a high level of validity, as do other studies that assess the acceptance of usability and learning environment in a virtual reality simulator for laparoscopic surgery[23], thus, in a study carried out in England, with a laparoscopic cholecystectomy training simulator, ten doctoral students and five volunteers from the department of general surgery were interviewed, among laparoscopic students and experts, to find out their perceptions about the usefulness of a procedure. simulator to help you better understand the surgical procedure of a cholescitectomy and practice surgical skills as well as decision making at the operative stage. Participants were asked to analyze the performance of a laparoscopy simulator; using 5five criteria: "ease of use, interactivity, visual realism, freedom of movement and effectiveness, and system stability" [2]; they concluded that game engine is an option with highly interactive virtual surgery training platform for pedagogical purpose, however, improvements are required to simulate and improvement in anatomy precision, as the different layers of tissues that a surgeon must actually operate in real surgery, the visual realism the integrity of procedure and the guide of medical experts [2].

Our results are consistent with various studies that showed that reality simulation virtual is significantly more effective than video trainers, as in the systematic review and metaanalysis of 31 randomized controlled trials, in which virtual reality training was compared with other training models or with no training; this meta-analysis concludes that "virtual reality simulation is significantly more effective than video trainers and at least as good as box trainers” [25]. In addition, other studies that investigated similarly to the present study recommended applying virtual reality to inexperienced medical students or surgeons novice in laparoscopic training [12]. 
The COVID 19 pandemic has changed paradigms in medical education, being an important change, suspension of face-to-face medical education [26] and in the case of medical internship, reducing direct contact with patients, to minimize the risks of contagion: In this scenario, the use of telemedicine, tele-teaching [27] and the use of simulators for medical education, is essential [28]. A key challenge for medical schools will be to simulate clinical encounters, between doctors, students and patients, therefore, proposals for the development of medical and surgical simulators and their respective socialization, evaluation, validation and technology transfer, are actually the steps to follow in the face of this health emergency scenario and in the future in the face of new similar pandemic scenarios.

The reliability of the internal consistency of the measurement elements of the questionnaire was evaluated by calculating Cronbach's alpha $(\alpha)$ test. Alpha reliability was considered acceptable, with values ranging between 0.832 for the Learning Environment and 0.898 for the Usability of Virtual Reality.

In this sense, the deductive and/or confirmatory approach of the proposed simulator for laparoscopic surgery training in virtual reality was mainly valid according to the results found.

These results support the incorporation of these virtual learning technologies based on simulation in medical education, especially in these times of health emergency. As concluded in the study "Simulations and Virtual Learning Supporting Clinical Education During the COVID 19 Pandemic", which indicates the urgent need to considering the benefits of simulation-based healthcare environments in Medical schools [28].

In conclusion, a simulator based on virtual reality was developed, allowing the training of laparoscopic surgery practices to medical students as a different alternative in a virtual world with different levels of manipulation. The environment that was recreated with the simulator creates an environment for learning and usability suitable for medical students by having simulated a realistic environment; this is due to Unity, which was very supportive in terms of the textures of the elements and the models used. Virtual reality technology was successfully used in the educational field since both the hardware and software parts were combined in this project and the sensors to interact with the entire virtual environment and the 3D models and animations. The results showed that $85.85 \%$ of the surveys carried out were positive for the learning environment area and $81.18 \%$ of the positive surveys for the Usability area, so it is concluded that the proposal developed can help in the training of medical students procedurally and practically for the development of skills in laparoscopic surgery.

As future work, it is suggested that more in-depth studies be carried out that allows increasing the correlation of Measurement Items Perceived Learning Effectiveness and Satisfaction with Immersion for the learning environment, as well as between Freedom of movement with the level of realism in the virtual environment. and with the level of realism when performing tasks.

\section{ACKNOWLEDGMENT}

To the Universidad Católica de Santa María, ArequipaPerú which has financed the approved project with Resolution 25181-R-202018 granted for the development of the article.

REFERENCES

[1] E. Yiannakopoulou, N. Nikiteas, D. Perrea, and C. Tsigris, "Virtual reality simulators and training in laparoscopic surgery," International Journal of Surgery, vol. 13. 2015.

[2] J. Zhang et al., "Development of laparoscopic cholecystectomy simulator based on unity game engine," Proc. - CVMP 2018 15th ACM SIGGRAPH Eur. Conf. Vis. Media Prod., Dec. 2018.

[3] F. Heinrich et al., "HoloPointer: a virtual augmented reality pointer for laparoscopic surgery training," Int. J. Comput. Assist. Radiol. Surg., vol. 16, no. 1, 2021.

[4] S. G. Izard, J. A. Juanes Méndez, and P. R. Palomera, "Virtual Reality Educational Tool for Human Anatomy,” J. Med. Syst., vol. 41, no. 5, 2017.

[5] S. W. Guadix et al., "Medical Student Concerns Relating to Neurosurgery Education During COVID-19," in World Neurosurgery, 2020, vol. 139.

[6] M. Pfandler, M. Lazarovici, P. Stefan, P. Wucherer, and M. Weigl, "Virtual reality-based simulators for spine surgery: a systematic review," Spine Journal, vol. 17, no. 9. 2017.

[7] W. K. Liou and C. Y. Chang, "Virtual reality classroom applied to science education," in 2018 23rd International Scientific-Professional Conference on Information Technology, IT 2018, 2018, vol. 2018January.

[8] S. González Izard, J. A. Juanes Méndez, P. Ruisoto Palomera, and F. J. García-Peñalvo, "Applications of Virtual and Augmented Reality in Biomedical Imaging,” J. Med. Syst., vol. 43, no. 4, 2019.

[9] V. Chheang et al., "Collaborative virtual reality for laparoscopic liver surgery training," in Proceedings - 2019 IEEE International Conference on Artificial Intelligence and Virtual Reality, AIVR 2019, 2019.

[10] J. C. Servotte et al., "Virtual Reality Experience: Immersion, Sense of Presence, and Cybersickness," Clin. Simul. Nurs., vol. 38, 2020.

[11] J. C. Vázquez-Minero et al., "Utilidad de la simulación de realidad virtual en la residencia de cirugía de tórax en México,” Neumol. Cir. Torax, vol. 77, no. 1, 2018.

[12] C. Jin, L. Dai, and T. Wang, "The application of virtual reality in the training of laparoscopic surgery: A systematic review and meta-analysis," International Journal of Surgery, vol. 87. 2021.

[13] J. Pierce et al., "Comparative usability studies of full vs. partial immersive virtual reality simulation for medical education and training," in Studies in Health Technology and Informatics, 2008, vol. 132.

[14] D. Lerner, S. Mohr, J. Schild, M. Göring, and T. Luiz, "An immersive multi-user virtual reality for emergency simulation training: Usability study," JMIR Serious Games, vol. 8, no. 3, 2020.

[15] M. Li, S. Ganni, J. Ponten, A. Albayrak, A. F. Rutkowski, and J. Jakimowicz, "Analysing usability and presence of a virtual reality operating room (VOR) simulator during laparoscopic surgery training," in Proceedings - 2020 IEEE Conference on Virtual Reality and 3D User Interfaces, VR 2020, 2020.

[16] J. V. Taba et al., "The development of laparoscopic skills using virtual reality simulations: A systematic review," PLoS One, vol. 16, no. 6, 2021.

[17] Ö. Özcan-Top and F. McCaffery, "To what extent the medical device software regulations can be achieved with agile software development methods? XP—DSDM-Scrum," J. Supercomput., vol. 75, no. 8, 2019.

[18] T. C. E. Gale, A. Chatterjee, N. E. Mellor, and R. J. Allan, "Health worker focused distributed simulation for improving capability of health systems in Liberia," Simul. Healthc., vol. 11, no. 2, 2016.

[19] L. Li and T. Li, "Animation of virtual medical system under the background of virtual reality technology," Comput. Intell., 2021.

[20] Unity, "Unity VR," Unity VR, 2021. [Online]. Available: https://unity.com/es/unity/features/vr.

[21] K. Stepan et al., "Immersive virtual reality as a teaching tool for neuroanatomy," Int. Forum Allergy Rhinol., vol. 7, no. 10, 2017. 
[22] P. Nokelainen, "An empirical assessment of pedagogical usability criteria for digital learning material with elementary school students," Educ. Technol. Soc., vol. 9, no. 2, 2006.

[23] M. Barrett and J. Blackledge, "Evaluation of a Prototype Desktop Virtual Reality Model Developed to Enhance Electrical Safety and Design in the Built Environment," Environ. ISAST Trans. Comput. Intell. Syst., vol. 3, 2012.

[24] S. F. M. Alfalah, J. F. M. Falah, T. Alfalah, M. Elfalah, N. Muhaidat, and O. Falah, "A comparative study between a virtual reality heart anatomy system and traditional medical teaching modalities," Virtual Real., vol. 23, no. 3, 2019.
[25] M. Alaker, G. R. Wynn, and T. Arulampalam, "Virtual reality training in laparoscopic surgery: A systematic review \& meta-analysis," Int. J. Surg., vol. 29, pp. 85-94, May 2016.

[26] Mian, A., Khan, S. Medical education during pandemics: a UK perspective. BMC Med; vol. 18, no 100, 2020.

[27] Hollander, Judd E.; Carr, Brendan G. Virtually perfect? Telemedicine for COVID-19. New England Journal of Medicine; vol. 382, no 18, 2020.

[28] Tabatabai, Shima. Simulations and virtual learning supporting clinical education during the COVID 19 pandemic. Advances in Medical Education and Practice; vol. 11, p. 513, 2020. 